\title{
Microbusinesses in
}

Australia: a Robust Definition

\section{Darius Pfitzner ${ }^{1}$, John McLaren ${ }^{2}$}

Microbusinesses form an important basis for future entrepreneurial and economic development in Australia. The microbusiness sector contributes significantly to Australia's economy, its social fabric and its ability to evolve, innovate, incubate and meet changing economic demands. The objective of this paper is to examine the important role microbusiness plays in the Australian economy and to provide a formal definition of what constitutes a microbusiness. Traditionally business in Australia has been classified as being a 'small', 'medium' or 'large' with the additional categories of 'small to medium' (SME) or 'multi-national enterprises' (MNE). An additional complication is created when trying to determine if a business exists or if it is just a 'hobby'. Further to this, there is a lack of microbusiness specific data collected and published because the key regulatory and reporting agencies do no not recognise microbusinesses as a separate category or if they do, they are only included as a relatively unmonitored and unrepresented subset of small business. It is contended that Australia lacks an appropriately defined microbusiness category that could be used to create government support devices and steps to monitor their economic significance. This paper discusses the significant ramifications this has for businesses in general and the Nation's economy. Based on this analysis the paper sets out the criteria for the establishment of a new category for microbusiness.

JEL classification: H26, L52, M29, N80, O17.

Keywords: Teaching, Definition, Role, Microbusiness, Micro SME, Micro Enterprise, Micro Business, Small Business, Hobby, Business Categories, Black Economy, Economic Monitoring, Business Development, Cash Economy, Tax Evasion, Australia.

\footnotetext{
${ }^{1}$ College of Business and Law, Charles Darwin University, Australia.

${ }^{2}$ College of Business and Economics, University of Tasmania, Australia.
} 


\section{INTRODUCTION}

Microbusinesses form an important basis for future entrepreneurial and economic development in Australia. The microbusiness sector contributes significantly to Australia's economy, its social fabric and its ability to evolve, innovate, incubate and meet changing economic demands. The objective of this paper is to examine the important role microbusiness plays in the Australian economy and to provide a formal definition of what constitutes a microbusiness. Traditionally business in Australia has been classified as being a 'small', 'medium' or 'large' with the additional categories of 'small to medium' (SME) or 'multi-national enterprises' (MNE). An additional complication is created when trying to determine if a business exists or if it is just a 'hobby'. Further to this, there is a lack of microbusiness specific data collected and published because the key regulatory and reporting agencies do no not recognise microbusinesses as a separate category or if they do, they are only included as a relatively unmonitored and unrepresented subset of small business. It is contended that Australia lacks an appropriately defined microbusiness category that could be used to guide the creation of laws, government support systems and services and instrumentsto monitor their economic significance.

Microbusinesses are critical to the functioning of any economy and the communities within which they operate. Globally, microbusinesses are recognised as the most prolific of all businesses and are seen playing a significant economic and social role in communities (Holmes, 2001). It is also recognised, across a variety of disciplines, that microbusinesses are significant economic actors in national, regional, and local economies (Acs Z. \&., 2004; Acs Z. \&., 2005; Baumol, 1968; Deller, 2010; Diochon, 2014; Fischer, 2003; Houston, 2017; Poutziouris, 1997; Mir Shahid, 2016; Servon, 2010).

Microbusinesses normally have close ties to the community within which they operate, typically providing economic and social benefits such as employment opportunities and as places of social interaction. Muske (Muske, 2007) highlight this relationship with local community

when they propose that because microbusiness owner-operators normally call the community home they have close connections to both the local area and associated communities. They extend this proposition with the suggestion that because of this close association with the community microbusiness owner-operators tend to have higher levels of perceived responsibility to the community. Other researchers have proposed that this connection to the local context sees microbusiness reflecting the priorities and uniqueness of the local community (Mitchell, 1999, p. 18; Coca-Stefaniak, 2009; Shaw, 2007) and that there is a tendency to be more philanthropic within the community through such activities as funding local community events (Madden, 2006; Shaw, 2007; Service, 2005, p. 29).

These traits imply a somewhat closed monetary cycle within a community with microbusiness having a significant impact on the speed and multiplier of any such cycle. This impact would be somewhat dependent on the performance of microbusinesses within that community. In this case, the optimization of microbusiness performance within a community can only be achieved if location specific microbusiness data is collected and reported. 
Microbusinesses have been overlooked as a separate category as they are included as an unmonitored and unrepresented subset of small business in Australia. Yet, the microbusiness sector contributes greatly to Australia's economy and its ability to evolve, innovate, incubate and meet changing economic demands. This paper proposes that Australia needs to formally treat Microbusinesses as a separate category from the Small Business category and in doing so address the key issues related to microbusiness and the lack of support, regulation and monitoring.

The Australian Bureau of Statistics (ABS) defines microbusinesses as those businesses that actively trade with less than five employees. According to the ABS, there are 1,792,525 microbusinesses (ABS, 2017) in Australia however it is not possible to accurately identify their impact on the Australian economy due to a lack of microbusiness specific data. For example, despite $85 \%$ of all firms in Australia being microbusinesses it is not possible to identify their economic impact relative to key economic dimensions such as the impact on GDP, total turnover and value of salaries let alone social dimensions (ABS, 2002). This data is simply unavailable because microbusinesses are, in most case, treated under the small business category despite there being a significant difference between the two.

The potential difference between micro and small business has been magnified with the Australian Taxation Office (ATO) announcing that from 2018 the small businesses company tax rate will apply to turnovers up to AUD50 million in the income year which is equivalent to an average weekly turnover of $\$ 943,396$ (ATO, 2017b). Businesses with these types of turnover bear little resemblance to microbusinesses and given microbusinesses are not treated separately by the ATO it is suggested that laws covering businesses with such large turnovers cannot possibly account for the unique needs of microbusiness.

The difference between micro and small business is further accentuated by comparing their structural and operating environments. For example, the small business that is turning over AUD50 million is likely to have considerable infrastructure, monitoring and control systems, staff with specific skills, knowledge and experience, a formal management structure and tailored financial and accounting systems. However, at the other end of the spectrum where you might find microbusiness as described under the ABS's definition (ABS, 2002) we see organisations that look very different. For example, a microbusiness is likely to be cash based, lack any formal systems, be self-financed with limited resources and capital, lack any formal structure and have minimal if no financial or accounting systems.

The lack of data describing microbusiness as a separate category has a direct impact on the performance of different business categories in Australia. The evidence for this contention is found in the fact that microbusiness as a separate category is rarely discussed in any quantitative or qualitative manner in Australia. The category of 'Small Business' is the primary focus of broader economic discussions, debates and published information without any substantive delineation between a small or microbusiness. As a result, the needs of microbusinesses which are a significant portion of Australia's small businesses and their economic impact is not being adequately promoted, and as a result, the potential economic and social benefit to Australian is not being maximised. This lack of recognition for microbusiness is highlighted when it is observed that the Australian government describes 
small businesses as 'the engine room of our economy' (Government, 2015) while not acknowledging the reality that microbusinesses comprise over $91 \%$ of the small business category (ABS, 2017).

However, to demonstrate that the creation of an official and detailed category for microbusiness might be worthwhile it is necessary to look at the European Union (EU) that does collect and report on key economic data for this category. Labelled 'Micro SME's' in the EU, microbusinesses are described as having less than ten employees and less than $€ 2$ million in turnover or less than $€ 2$ million on the Balance sheet total (Muller, 2015, p. 83). It is noted that this category is somewhat comparable with the ABS's definition of microbusiness, described above. The similarity is compounded when one observes the fact that Micro SMEs comprise around 92\% of all SME's in the EU (Muller, 2015, p. 3) which is virtually similar to the situation in Australia’s 91\% (ABS, 2017).

Given the similarity between the EU's Micro SME category and Australia's microbusiness category, it is interesting to analyse the statistics for the EU's Micro SME category in order to assess the likely economic impact microbusinesses might have on the Australian economy. The 2015 Annual Report on European SME's provides an overview of the past and forecasted performance of SMEs from 2008 to 2016, and evaluates in greater detail the contribution of SMEs to employment creation (Muller, 2015, p. 3). The report clearly delineates between Micro, Small and Medium enterprises and provides key economic factors for each category such as total employment and total value add. For example, in 2014 Micro SME's contributed to $29.2 \%$ of total employment and $21.1 \%$ of the total value to the EU economy (Muller, 2015, p. 8).

This paper investigates key limiting factors experienced by microbusinesses in Australia and how the lack of a detailed formal definition of microbusiness has not been able to guide policy development and its impact on the economy and social fabric. Based on this investigation the paper proposes that a new Australian 'microbusiness category' should be developed based on the criteria set out below. There are many aspects of microbusiness in Australia that impact on the economy and people engaged in this type of business activity. These aspects, including assessing the performance or lack of performance due to limited capital, education, compliance costs and taxation implications with cash only businesses have not been examined in this paper. They are issues that will be considered in future publications. The main objective is to develop a formal definition for microbusiness in Australia and the recognition that these businesses have a major impact on the economy.

\section{CRITERIA FOR A NEW MICROBUSINESS CATEGORY}

The Australian government needs to collect and publish data specific to microbusinesses in order to encourage the debate on, and planning for the support and development of these types of businesses which are a key economy factor in Australia's economy. To facilitate these types of activity, Australia needs a broadly accepted, well defined and formal business category for microbusiness. Such a business category should appropriately account for the 
key characteristics of microbusinesses for key stakeholders when considering businesses in within this category. The characteristics are as follows.

2.1 Broad characteristics displayed by microbusinesses

- Limited turnover;

- Often operate on a cash basis or with a large proportion of cash transactions;

- Have limited resources and capital;

- Tend to lack forward planning and operate with a more immediate focus (e.g., day-to-day or week-to-week);

- Lack of formal operating processes and systems;

- Have minimal, if no financial or accounting systems;

- Are normally self-financed;

- Tend to lack any formal structure; and

- The owners lean towards having limited formal business knowledge or skills.

In relation to the above characteristics it is proposed that the definition of a microbusiness must include the following criteria:

- Formal Business Registration - The business must have as a starting point an Australian Business Number (ABN). If not, then it would be defined as a hobby and not a business.

- Operating Capital - The business must have limited operating capital of less than AUD50,000. The microbusiness might, in fact, start with no capital.

- Turnover - The business must have a relatively low annual turnover of less than AUD250,000.

- Profit - The business must be seeking to be making an annual profit which when made should be less than AUD150,000. If profit is not a motive, then the activities would fit the definition of being a hobby.

These proposed criteria are designed to reflect the specific capacity limitations of microbusinesses. The criteria focus on businesses that are formally recognised but are very small with significant resource and capability restrictions. By only recognising businesses that have an $\mathrm{ABN}$ it is easier for Australian governments at both the Commonwealth and State and Territory levels to target support mechanisms and measure their effect with data specific to these microbusinesses. An Australian Business Number (ABN) is a unique number that identifies a business to the government and community. Importantly, ABN registration details become part of the Australian Business Register (ABR) which the Australian Taxation Office (ATO) maintains on behalf of the Commonwealth. This enables 
organisations like the ATO and ABS to access important data related to individual businesses that can be used for modelling economic activity in Australia. By limiting operating capital, turnover and profit those business that are capacity and capability poor will be captured by this type of data which may be available from the ATO and the ABS.

The criteria used for the definition does not include any reference to the number of employees engaged in the microbusiness. The ABS formally recognises microbusinesses as having less than 5 employees. This attempt to define microbusiness in this way is totally rejected, and the reason for this is that the number of employees is somewhat misleading when trying to describe microbusiness especially where there is an owner requiring some level of income from the business, and yet there are four employees drawing salaries or wages.

For example, where a business has four employees, it is suggested that the turnover, systems, and organisation required to maintain an income for the owner and four wages is better represented by the category of Small Business. If the owner and each employee is receiving an income equal to Australia's 'Full-Time Adult Average Weekly Total Earnings,' which is AUD1,628.10 (ABS, 2017c), then the business would need to be expending the equivalent of AUD431,420 each year just on the wages. Because this cost needs to be covered by gross income, the turnover required would be significantly higher again, and so it is contended that any organisation that has turnovers at these levels would not conform to any of the previously described characteristics of a microbusiness and would be better described as a small business.

The following examples, although fictitious, are based on actual microbusinesses that are being recognised as microbusinesses under the above criteria.

\subsubsection{Jill the Tarot Card Reader}

Jill, the Tarot Card Reader, works part-time for a major retail chain while earning money on the side from reading tarot cards at two evening and a full day market each week, say approximately 120 markets per year. She does the occasional readings at home for customers through an advertisement in the social media page. Jill charges AUD35 for a reading that lasts 15-20 minutes and completes around seven readings per market. She only takes payment in cash, has no business-related tax deductions and her capital investment totals two decks of Tarot cards, a foldout card table, a table cloth and two foldout deck chairs. She does have an ABN which is required to rent a space at the local markets which cost AUD45 per market. Jill is well-known in the local community, and the money she earns from Tarot reading is spent locally on day-to-day living expenses such as cat food, house repairs, and garden maintenance.

Before deciding if Jill's tarot card reading activities classify her as a microbusiness, it is necessary to ensure that Jill is not better described as conducting a 'hobby' and that she is 'carrying on a business' (Ferguson v FCT, 1979). With a reported yearly market turnover of around AUD19,400 and expenses of around AUD5,400, mainly rent, Jill’s activities can be 
seen as having a relatively significant profit aspect. In addition, she trades regularly, pays rent, has some capital investment and has a social media presence used to attract customers. This all suggests that Jill is 'carrying on a business' in a systematic and business-like manner with a commercial flavour and as such is not conducting a hobby.

Given that Jill is not engaged in a hobby but is carrying on a business, can her activities be described as that of a microbusiness? First, Jill's business displays all the characteristics of a microbusiness listed above. Second, the business conforms to all four proposed Microbusiness criteria in that she has an ABN, her capital is less than \$50,000, her annual turnover is less than $\$ 250,000$, and her annual profit is less than $\$ 150,000$. As such Jill's tarot card reading business is a microbusiness.

So, what are the benefits of recognising Jill as a microbusiness?

Currently, Jill is using her business to top-up her weekly income with no immediate intentions to expand or develop the business. This would suggest that there is no need for the government to consider how to support her type of business from a development perspective. However, the existence of the Cash or Black Economy is an issue in Australia, and given that Jill only takes cash payments it may be in the Australian government's interest to consider ways in which her microbusiness may be monitored. Although there may be some negative connotation related to the potential underreporting of income tax, Jill plays a key social role in the local markets, and the income she makes is all spent within her community.

The Australian government should be concerned with this type of situation as it can result in a few negative outcomes for Australia such as the under reporting of economic activity, reduced income tax revenue and collection of the Goods and Service Tax (GST). Australia needs to formally recognize businesses like Jill's as microbusinesses in order to be able to identify the impact these businesses have on the Australian economy and to design policy to encourage microbusiness away from the black economy.

\subsubsection{Mr. Bean the Coffee Van Man}

Mr. Bean, the Coffee Van Man, built his own coffee van from an old Caravan worth \$200 and refurbished and fitted it out for \$15,000 including a second hand commercial coffee machine and stainless-steel sink. He operates a drive through coffee station 44 weeks a year at the local post office 5 days a week starting at $6.00 \mathrm{am}$ and finishing at $1.00 \mathrm{pm}$ each day. Although there is no formal rental agreement with the post office owner, there is a successful gentlemen's agreement that includes rent in the form of free coffees for the owner and post office staff. In addition to his morning drive-through stand, he also sells coffee at 6 public events per year for which he hires several people, mainly family, to help serve customers and he pays the employees cash.

Mr. Bean does have an ABN for tax purposes. He also needs the ABN so that he can have a wholesale purchaser account for stock such as take-away cups, sugar, milk, and coffee. He also needs the ABN to obtain food vendor registration with the local council, to obtain a food handling certification from the Department of Health and to acquire business insurance. 
Although he does have a smart card reader for cashless transactions, most transactions are cash. Mr. Bean's has a taxable annual income of AUD57,000 from a reported annual turnover of AUD103,000 and costs of AUD46,000.

Mr. Bean is 'carrying on a business' in a systematic and business-like manner with a commercial flavour and as such is not conducting a hobby. He has an ABN, his capital is less than AUD50,000, his annual turnover is less than AUD250,000, and his annual profit is less than AUD150,000, and so he fits the categorized of a microbusiness. It is fairly evident that there are black economy issues related to Mr. Bean and his handling of cash including cash-in hand payments to third parties. However, in this case, there are a number of extra issues such as the lack of protection for casual staff, the lack of accounting systems that might be used to improve the productivity and profitability of the business and a lack of knowledge about the taxation system.

\subsubsection{Jan’s Tea Kettle}

Jan is 66 years of age and has no superannuation but owns the registered business, 'Jan's Tea Kettle' which is a small food outlet in an industrial area. The business operates out of an old corner store, rented for $\$ 450$ rent per week, selling takeaway foods such as sandwiches, pies, pasties, sausage rolls, coffee and drinks for morning and afternoon tea. The shop rent is relatively low because Jan attended school with the owner of the premises and is still good friends with them. The business owns two glass fridges, a stainless-steel food preparation bench, two pie warmers, a sandwich toaster, a coffee machine, two sets of plastic outdoor furniture, a serving counter and a cash register. The equipment is old and only worth about AUD5,000 on the secondhand market. Jan works in the shop Monday to Friday and employs one part-time staff member to help serve and prepare sandwiches from 9.00 am to $2.00 \mathrm{pm}$ Tuesday to Saturday and an extra casual employee on Saturday to help the part-time staff member. Because Mondays do not have many customers, Jan runs the shop by herself on that day.

'Jan's Tea Kettle' is a bit of a social gathering place and everyone in the industrial estate knows Jan on a first name basis. The business turns over AUD190,000 per year, she tracks and manages the quarterly GST returns using a simple accounting application and employs an accountant to do her yearly tax return. Jan has an ABN which allows her to have a wholesale account with the local wholesaler. Jan likes being her own boss, and she spends her money locally on rent and day-to-day living expenses.

Unfortunately, Jan may need to close the business down because although she has been able to maintain a small personal yearly income of AUD45,000, the business equipment is very old and needs replacing. However, Jan has no savings to cover the replacement cost of the equipment which is around AUD50,000, and she does not think she will be able to obtain a bank loan.

Jan is 'carrying on a business' in a systematic and business-like manner, with a commercial flavour and is therefore not conducting a hobby. Jan's business conforms to all four of the 
proposed Microbusiness definition criteria in that she has an ABN, her capital is less than AUD50,000, her annual turnover is less than AUD250,000, and her annual profit is less than AUD150,000. Jan's Tea Kettle is a microbusiness that has a positive economic impact through rent, wholesale expenditure, wages, personal expenditure, and tax. Without appropriate support, Jan's Tea Kettle is likely to close, and Jan would start drawing on a government pension.

\subsubsection{Peter the Panel Beater}

Peter the panel beater is a backyard mechanic who buys slightly damaged cars from the local car auctions, fixes them up and sells them for cash. He works fulltime as a manager for a local car dealership earning a taxable income of AUD98,000 per year and is paying a mortgage on the family home. Afterhours and on the weekends, he works out of his shed in the backyard that he has fitted out with AUD35,000 worth of panel beating equipment. He turns over between 10-15 cars per year advertising the cars for sale on local bulletin boards, through the local buys-swap-sell, and in newspapers. Each car costs between AUD1500-3500 to buy and he tries to turn each car around for minimal effort and cost and maximum profit. He turns over an average of AUD48,000 per year with an average yearly profit of AUD16,000. Peter is well known in the local ethnic community, and the money he earns from fixing cars is spent locally on day-to-day living expenses such as food, school fees and cloths for his family and the occasional family treats like going to the theatre or a caravan holiday up the coast.

Peter is 'carrying on a business' in a systematic and business-like manner with a commercial flavour and as such is not conducting a hobby. He has capital of less than AUD50,000, his annual turnover is less than AUD250,000, and his annual profit is less than AUD150,000 however, he does not have an $\mathrm{ABN}$, and none of his turnover or profit is reported, and so he cannot be categorised as a microbusiness. Peter is clearly a microbusiness but does not conform to the proposed definition.

The proposed microbusiness category is the first step towards encouraging businesses like Peter's to formalise and legitimise so that they can be accounted for nationally and encouraged to develop to the benefit of the Australian economy and society. Toward these ends, the proposed microbusiness category would allow for the collection of specific microbusiness data and support the development of incentives and support schemes. This, in turn, would encourage the owners to comply with the law and potentially expand becoming more successful for the owners and productive for the nation.

\subsubsection{Jenny’s Jewellery}

Jenny imports jewelry made in Bali and until recently sold the jewelry through a stand at the local farmer's markets. However, recently she stopped selling at the markets and took the bold step of signing a lease of premises at a cost of AUD350 per week. By renting premises, Jenny needed to obtain an ABN. Jenny wishes to see if she can be more successful with a 
'proper shop,' and so the lease is for a relatively affordable small shop space in a new shopping complex on the outskirts of town. The shop is call Jen's Australian Handmade Jewelry. The shop fit-out cost AUD20,000 and the current stock value is AUD15,000.

After six months trading Jenny thinks she might be able to report a first-year turnover of around $\$ 150,000$ with a profit of $\$ 30,000$ although she would have only drawn around $\$ 10,000$ personally and would still be drawing down her savings. Jenny is positive about the future and thinks she can increase her profit significantly although she does not really know how this will happen. She works in the shop six days a week and pays a friend cash to help on evenings and Sunday. She does not know if she should be paying GST and currently plans to do her own tax to save money. She has a manual cash register and does not have any stock keeping or accounting systems.

Clearly, Jenny is now 'carrying on a business' in a systematic and business-like manner, with a commercial flavour and is not conducting a hobby. Jenny's business conforms to all four proposed Microbusiness criteria in that she has an ABN, her capital is less than $\$ 50,000$, her annual turnover is less than $\$ 250,000$, and her annual profit is less than $\$ 150,000$. As such Jill's jewellery business is a microbusiness.

Jenny's business is a classic example of an entrepreneurial individual with a business in the microbusiness phase that clearly displays all the classic characteristics of a microbusiness. However, Jenny may need financial and government support in the future otherwise thee is the potential for her to fail in her business and lose her investment of time and money. This would be a loss to the Australian economy because with the right type of support her business could be successful and be productive.

\subsubsection{Lee the IT Consultant}

Lee is a home-based Information Technology (IT) consultant trading under the registered business name of 'Lee IT' developing websites for local businesses and individuals. Lee is twenty-two years of age, has a Bachelor of Information Technology Degree and has been playing with computers and programming since he was six years old. Lee is only really known to a small group of close online gamer friends, and the money he earns is spent locally on day-to-day living expenses, more IT equipment, and computer games.

Lee has around $\$ 15,000$ worth of computer and network equipment setup in the spare room of his parents' house. Lee’s reported yearly personal income is around \$45,000 and has almost no tax deductions. Most of his business comes from word of mouth and he prefers to trade in cash although he does take the occasional online payment through his personal PayPal account and only issue invoices when one is asked for by the client.

Lee is 'carrying on a business' in a systematic and business-like manner, with a commercial flavour and as such is not conducting a hobby. He has capital of less than $\$ 50,000$, his annual turnover is less than $\$ 250,000$, and his annual profit is less than $\$ 150,000$ however he does not have an $A B N$ which means he falls outside the definition as a microbusiness. Clearly the other characteristics of the proposed definition of a microbusiness, however, it is important 
that the microbusiness must have a registered $A B N$ otherwise they fall into the category of being a hobby. An ABN is a perfect device around which data can be collected, and business support initiatives might be designed by governments to support these types of business. This approach also keeps the list of defining criteria simpler and easier to use. What is important is the fact that Lee needs to be encouraged to formalise and legitimize his business by at least taking the first step and obtaining an ABN. The proposed microbusiness definition and its criteria will allow specific data to be collected from these types of businesses and enable governments to develop incentive and support schemes to encourage Lee to legitimise his microbusiness and become more successful not only for himself but to increase the productivity of the nation.

In order to support the development of microbusinesses in Australia, policy makers and governments will need to undertake and encourage the following activities:

- Industry and market research;

- Data collection;

- Research both academic and applied;

- Specific income tax related policy development;

- The design and development of financial packages and services;

- The design and development of prudential services;

- The design and development of a peak body and their representations to industry and government;

- The development of laws and monitoring and support systems.

\section{CONCLUSION}

The main objective of this paper was to highlight the importance of microbusinesses in Australia and their contribution to the Australian economy. In order to achieve this objective, the economic contribution made by microbusiness has to be measured and more importantly the category of what is, in fact, a microbusiness has to be defined. This paper has clearly established the criteria that should now be used to define microbusiness in the future. The criteria include formal business registration with an Australian Business Number (ABN); operating capital of less than AUD50,000; turnover of less than AUD250,000 and the business must be making an annual profit which less than AUD150,000. If profit is not a motive, then the activities are not a microbusiness but a hobby.

As has been discussed above, there is nothing insubstantial about the number of microbusiness in Australia, or the impact microbusinesses have on Australia's social and economic fabric. Despite this reality, Australia does not have a detailed category for microbusiness and does not collect and report comprehensive economic and performance data for these types of business. Australia cannot afford to continue to ignore this significant portion of its business population. The Australian government needs to start collecting and 
publishing data specific to microbusinesses in order to encourage research into, debate around, and planning for the support and development of these types of businesses. To support these outcomes, Australia needs a new business category, and this paper is the start of the discussion of what constitutes a microbusinesss.

\section{References}

ABS. (2002, Oct 23rd). 1321.0 - Small Business in Australia. Retrieved Nov 26th, 2013, from http://www.abs.gov.au/AUSSTATS/abs@.nsf/mf/1321.0

ABS. (2017). Businesses by Industry Division by Statistical Area Level 2 by Employment Size Ranges, June 2014, June 2015 \& June 2016. Australian Bureau of Statistics. Retrieved June 1st, 2017, from http://www.abs.gov.au/AUSSTATS/abs@.nsf/DetailsPage/8165.0Jun\%202012\%20to \%20Jun\%202016

ACCI. (2012). ACCI National Red Tape Survey. Australian Chamber of Commerce and Industry.

ACCI. (2016). Small Business Survey | March Quarter 2016. Australian Chamber of Commerce and Industry. Retrieved Sept 4th, 2017, from https://www.australianchamber.com.au/wp-content/uploads/2018/01/Small-BusinessSurvey-March-2016.pdf

Acs, Z. \&. (2004). Job creation and persistence in services and manufacturing. Evolutionary Economics, 14, 209-325. Retrieved from https://link.springer.com/article/10.1007/s00191-004-0194-z https://doi.org/10.1561/0300000004

Acs, Z. \&. (2005). Entrepreneurship, innovation and technological change. Foundations and Trends in Entrepreneurship, 1(5), 1-65.

APRA. (2017). Reporting Standard ARS 701.0: ABS/RBA Definitions for the EFS Collection. Australian Prudential Regulation Authority. Sydney: Australian Prudential Regulation Authority. $\quad$ Retrieved Sept 4th, 2017, from http://www.apra.gov.au/adi/PrudentialFramework/Documents/ARS\%20701.0\%20AB SRBA\%20Definitions.pdf

ASIC. (2018, March 12th). Small Business Overview. Retrieved April 24th, 2018, from Australian Securities \& Investments Commission: http://asic.gov.au/forbusiness/your-business/small-business/small-business-overview/

ATO. (2015, May 4th). Entity Size. Retrieved Sept 1st, 2017, from Australian Taxation office: https://www.ato.gov.au/about-ato/research-and-statistics/in-detail/taxationstatistics/taxation-statistics-2012-13/?page=4\#Entitysize

ATO. (2017, May 22nd). Definitions. Retrieved Sep 1st, 2017, from Asutralian Taxation 
office: https://www.ato.gov.au/Business/Small-business-entityconcessions/Eligibility/Definitions/

Australia Government. (2013). Regulator engagement with small business: Productivity Commission research report. Melbourne: Productivity Commission (issuing body).

Australia, T. P. (1990). Small Business in Australia: Challenges, Problems and Opportunities. Report by the House of Representatives Standing Committee on Industry, Science and Technology. Canberra: Canberra Publishing and Printing.

Basu, S. (1986). Problems of Small Business. Economic Papers: A journal of applied economics and policy, 5(4), 92-110.

Baumol, W. J. (1968). Entrepreneurship in economic theory. American Economic Review, 58, 64-71.

Coca-Stefaniak, J. A. (2009). Town centre management models: A European perspective. Cities, 26, 74-80. https://doi.org/10.1016/j.cities.2008.12.001

Deller, S. C. (2010). Spatial Variations in the Role of Microenterprises in Economic Growth. Review of Regional Studies, 40(1), 71-97.

Diochon, M. (2014). A baseline study of entrepreneurship among first nations women in the Atlantic region . Small Business \& Entrepreneurship, 27(1).

Ferguson v FCT, 9 ATR 873; 79 ATC 4261 (Federal Courst of Asutralia 1979).

Fischer, E. \&. (2003). Support for Rapid-Growth Firms: A Comparison of the Views of Founders, Government Policymakers, and Private Sector Resource Providers. Small Business Management, 41, 346-365. https://doi.org/10.1111/1540-627X.00087

Freudenberg, B. C. (2017). Tax Literacy of Australian Small Businesses. Journal of Australian Taxation, 18(2), 21-61.

FWA. (n.d.). Unfair Dismissal. Retrieved Sept 4th, 2017, from Fairwork Ombudsman: https://www.fairwork.gov.au/ending-employment/unfair-dismissal

Gartner, W. B. (1988). Who is an entrepreneur?” is the wrong question. American journal of small business, 12(4). https://doi.org/10.1177/104225878801200401

Government, A. (2015). Budget 2015: growing jobs and small business. The Commonwealth of Australia.

Government, Australian. (2015). Budget 2015: growing jobs and small business. The Commonwealth of Australia.

Holmes, S. \&. (2001). Definitions of Small Business. Final Report. Canberra: Australian Information Brokers.

Houston, D. \&. (2017). City economies and microbusiness growth . Urban Studies, 54(14), 
3199-3217.

Isle, M. a. (2015). Calm waters: GST and cash flow stability for small businesses in Australia. eJournal of Tax Research, 13(2), 492.

Madden, K. S. (2006). How and why small to medium size enterprises (SMEs) engage with their communities: An Australian study. International Journal of Nonprofit and Voluntary Sector Marketing, 11(1), 49-60. https://doi.org/10.1002/nvsm.40

Mir Shahid, S. \&. (2016). A conceptual model of critical success factors for Indian social enterprises", World. Entrepreneurship, Management and Sustainable Development, 12(2), 113-138.

Mitchell, J. (1999). Business improvement districts and innovative service delivery. School of Public Affairs, The City University of New York, The PriceWaterhouseCoopers Endowment for The Business of Government.

Muller, P. C. (2015). Annual report on European SMEs 2014/2015: SMEs start hiring again. Final report. European Commission. doi:10.2873/886211

Muske, G. W. (2007). Small businesses and the community: Their role and importance within a state's economy. Journal of Extension, 45(1).

Parliament of the Commonwealth of Australia. (1990). Small Business in Australia: Challenges, Problems and Opportunities, Report by the House of Representatives Standing Committee on Industry, Science and Technology. Canberra: Canberra Publishing and Printing Co. Fyshwick, ACT.

Poutziouris, P. O. (1997). The [Re]-Generation of Family-Business Entrepreneurship in the Balkans. Family Business Review, 10(3), 239. https://doi.org/10.1111/j.1741$\underline{6248.1997 .00239 . x}$

Sensis. (2017). Sensis Business Index March 2017: A survey of confidence and behaviour of Australian small and medium businesses. Sensis Pty Ltd. Retrieved Sept 4th, 2017, from

https://www.sensis.com.au/asset/PDFdirectory/SensisBusinessIndex_March2017.pdf

Service, A. C. (2005). Giving Australia: Research on philanthropy in Australia. Canberra: Department of Family and Community Services.

Servon, L. F. (2010). The Five Gaps Facing Small and Microbusiness Owners: Evidence From New York City. Economic Development Quarterly, 24(2), 126-142. https://doi.org/10.1177/0891242409354899

Shaw, S. \&. (2007). Social entrepreneurship: Theoretical antecedents and empirical analysis of entrepreneurial processes and outcomes. Small Business and Enterprise Development, 14(3), 418-434. https://doi.org/10.1108/14626000710773529

T., K. K. (1985). Small Scale Manufacturing in Ireland. Economic and Social Research 
AABFJ | Volume 12, no. 3, 2018

Institute, 34.

Woodhouse, A. (2006). Social capital and economic development in regional Australia: A case study. Rural Studies, 22, 83-94. doi:10.1016/j.jrurstud.2005.07.003 https://doi.org/10.1177/0042098016680520 